\title{
Bacterial toxins and the Rho GTP-binding protein: what microbes teach us about cell regulation
}

\author{
Carla Fiorentini $^{1,3}$, Michel Gauthier ${ }^{2}$, Gianfranco Donelli ${ }^{1}$ and \\ Patrice Boquet $^{2}$ \\ 1 Department of Ultrastructures, Istituto Superiore di Sanità, Viale Regina Elena \\ 299, 00161 Rome, Italy \\ 2 INSERM U452 Faculté de Médecine, avenue de Valombrose, 06107, Nice \\ Cedex 2, France \\ ${ }^{3}$ corresponding author: C. Fiorentini, tel: +39-6-49903006; \\ fax: +39-6-49387140; e-mail: fiorentini@ul.net.iss.it
}

Received 22.12.97; revised 31.3.98; accepted 13.5.98

Edited by R.A. Knight

\begin{abstract}
In the present review activities of two bacterial toxins, Clostridium botulinum exoenzyme $\mathrm{C} 3$ and Escherichia coli CNF1, both acting on the GTP-binding protein Rho are analyzed. Proteins belonging to the Rho family regulate the actin cytoskeleton and act as molecular switches in a number of signal transduction pathways. C3 and CNF1 have opposite effects on Rho thus representing useful tools for studies on cell division, cell differentiation and apoptosis.
\end{abstract}

Keywords: Rho; C3; CNF1; cell regulation

\begin{abstract}
Abbreviations: CNF, cytotoxic necrotizing factor; GEF, guanine exchange factor; GAP, GTPase activating protein; LPA, lysophospatidic acid; ROK, Rho kinase; PIP2, phosphatidyl-inositol-4,5phosphate; PI4-P, phosphatidyl inositol 4 phosphate; ECM, extracellular matrix; SRE, serum responsive element; SRF, serum response factor
\end{abstract}

\section{Introduction}

Almost 10 years separate the discovery of a toxin which exerts an inhibitory activity on the p21 Rho small GTPase: the Clostridium botulinum exoenzyme C3 (Aktories et al, 1987; Rubin et al, 1988; Chardin et al, 1989) from that of a toxin which activates the same GTP-binding protein: the cytotoxic necrotizing factor 1 (CNF1) from Escherichia coli (Flatau et al, 1997; Schmidt et al, 1997). Exoenzyme C3 and CNF1 are now major tools for laboratories working on the actin cytoskeleton and signal transduction.

Aims of the present review are (i) to analyze the activities of these two bacterial toxins having opposite effects on the GTP-binding protein Rho; and (ii) to examine how these toxins can provide clues for explaining roles played by Rho in cell division, cell differentiation or apoptosis.

\section{The GTP-binding protein Rho: a target for bacterial toxins}

Rho protein (Madaule and Axel, 1985), discovered shortly after Ras (Chang et al, 1982), and YPT1 (a Rab-like GTPase from Saccharomyces cerevisiae) (Gallwitz et al, 1983), belong to a family of regulatory molecules now grouped under the name of 'Ras superfamily'. This superfamily encompasses three main groups of proteins: Ras, Rho and Rab which differ according to their sequence homology and their function. A certain number of other GTP-binding molecules (Arf and Ran) which harbour similarities with Ras are now linked to this superfamily of proteins (Zerial and Huber, 1995). The Ras group (Ras, Rap and Ral) is implicated in signal transduction of mitogenic signals, the Rho, Rac and Cdc42 subgroup regulates the F-actin cytoskeleton and the Rab subfamily (Rab 1 to Rab 30) controls intracellular traffic (Downward, 1990). Small GTP-binding proteins are under an active form, and are thus able to trigger a cascade of signalling events when they are associated with GTP. Linked to GDP, they are in the resting state. An activated small GTP-binding protein becomes inactive by hydrolyzing GTP into GDP. GTP hydrolysis by small GTP-binding proteins alone is normally exceedingly slow. In association with a protein named GTPase activating protein (GAP), GTP hydrolysis is very rapid. Activation of small GTP-binding proteins is due to the removal of their bound GDP. The protein which performs this task is the guanine exchange factor (GEF). The simple removal of GDP from the small GTP-binding protein allows binding of GTP since there is a large excess in cells of GTP over GDP. Two polypeptide domains change their conformation in small GTP-binding proteins when the molecule is associated either with GTP or GDP. These polypeptides are called switches (Milburn et al, 1990). Switch 1 (residues 30 to 39 in Ras, 32 to 41 in Rho) corresponds to the Ras polypeptide contacting its downstream effector (in the case of Ras it is Raf) whereas switch 2 (residues 60 to 76 in Ras, 62 to 78 in Rho) is implicated in the GTP to GDP hydrolysis.

Rho is mostly localized in the cytosol, associated with a molecule (guanine dissociation inhibitor GDI) which maintains its conformation in the inactive form (linked to GDP) (Fukumoto et al, 1990). When a growth factor (derived from a lipid, lysophosphatidic acid (LPA)) binds to its receptor (belonging to a family of receptors acting through heterotrimeric $\mathrm{G}$ proteins), it activates Rho via the Rho exchange factor at the level of the membrane. This mechanism and its precise localization are still poorly elucidated. Activated-Rho has two main targets for the regulation of the actin cytoskeleton: a serine-threonine kinase named Rho kinase (ROK) (Matsui et al, 1996; Ishizaki et al, 1996) and a kinase inducing, by phosphorylation (on position 5 of the inositol ring), the formation of 
phosphatidyl-inositol-4,5-phosphate (PIP2) from phosphatidyl inositol 4 phosphate (PI4-P) (Chong et al, 1994; Ren et al, 1996). By regulating these two kinases, Rho might control the actin cytoskeleton by three mechanisms: (i) by acting on Rho kinase, it will provoke the bundling of actin filaments by directly (Amano et al, 1997) or indirectly (via phosphorylation of the myosin light chain phosphatase resulting in the inhibition of this enzyme) (Kimura et al, 1996) phosphorylating the myosin type 2 light chain allowing these molecules to associate with actin filaments and thereby provoking contractility (Fujihara et al, 1997); (ii) by locally raising the PIP2 concentration, Rho activates molecules bridging actin filaments and cell membraneassociated proteins such as vinculin (Gilmore and Burridge, 1996) ezrin, moesin or radixin (ERM group) (Hirao et al, 1996) and (iii) probably by provoking a PIP2 dependent actin polymerization (as described for Rac; Hartwig et al, 1995) by uncapping actin filament barbed ends (where addition of new actin subunits occurs). By these three mechanisms, Rho will allow extension of the cell surface (also called cell spreading). According to Cramer and Mitchison (1995), cell spreading results from actin polymerization at the cell periphery but also from the association of actin and myosin which induces cell contractility.

Rho also induces, by a mechanism implicating ezrin (a protein belonging to the ERM group), the formation of focal adhesion contacts (Mackay et al, 1997). Focal contacts are structures by which cells are anchored to the extracellular matrix $(E C M)$ via integrins. As we will see below, anchoring to ECMs through integrins is an indispensable step for the generation of intracellular signals leading to multiplication, differentiation or apoptosis.

In addition to activities on cell spreading and formation of focal contacts, Rho exhibits other functions. One is relative to the regulation of endocytosis. Rho-GTP has an inhibitory effect on the formation of clathrin-coated vesicles, implicated in receptor-mediated endocytosis (Lamaze et al, 1996). Conversely, Rho-GTP seems to favour pinocytosis (Schmalzing et al, 1996), another system of endocytosis, but requiring no clathrin coat. Another additional function of Rho is its activity in the progression of cell cycle (Olson et al, 1995).

How can toxins acting on Rho give us clues concerning the role of these GTP-binding proteins in cell regulation? We will describe first the structure and function of two toxins acting on Rho, exoenzyme C3 from $C$. botulinum and CNF1 from $E$. coli. Then we will examine the cell activities of these toxins.

\section{Exoenzyme $\mathrm{C} 3$ and CNF1: two bacterial toxins with opposite effects on the GTP-binding protein}

C3 is produced by some strains of $C$. botulinum (serotypes $C$ and $\mathrm{D}$ ) in addition to $\mathrm{C} 2$ toxin and neurotoxins (Rubin et al, 1988). C3 is not a true toxin but the $25 \mathrm{kDa}$ enzymatic moiety of a toxin. C3 activity on whole cells is difficult to assay since it cannot enter directly into the cytosol. To obviate this problem several toxins, called chimeric, have been prepared by genetic fusion associating $\mathrm{C} 3$ with the cell binding and membrane translocating polypeptides of diphtheria or Pseudomonas aeruginosa exotoxin A (Aullo et al, 1993; Boquet et al, 1995). Exoenzyme C3 is an ADP-ribosyltransferase which hydrolyzes NAD into ADP-ribose and nicotinamide and covalently links ADP-ribose to Rho Asparagine 41. Although asparagine 41 of $\mathrm{Rho}$ is in the switch 1 region (effector domain of Rho) (Sekine et al, 1989), it does not modify the architecture of the Rho effector domain sufficiently to block the interaction of Rho with the downstream effector ROK. However, ADP ribosylation of Rho blocks the translocation of Rho to the membrane resulting in the inhibition of Rho activity (Fujihara et al, 1997) (Figure 1).

CNF1 is a $110 \mathrm{kDa}$ toxin produced by certain pathogenic strains of $E$. coli (Donelli and Fiorentini, 1997). This toxin causes necrosis when injected in rabbit skin and multinucleation in cultured cells (Caprioli et al, 1983). In cultured cells, the toxin mainly induces the formation of actin stress fibers and promotes cell spreading (Fiorentini et al, 1988, 1995) mimicking effects obtained by microinjection of the dominant active mutant of Rho (Paterson et al, 1990). CNF1 acts on Rho by a new mechanism for a bacterial toxin. Indeed, CNF1 will make Rho permanently active without the necessity for its interaction with the Rho exchange factor. After CNF1 modification, Rho loses its ability, both intrinsic or mediated by GAP, to hydrolyse GTP into GDP

The loss of ability of Rho and RhoGAP to hydrolyse GTP into GDP is the result of an enzymatically mediated Rho protein modification, induced directly on the GTP-binding protein by CNF1. Indeed, CNF1 specifically acts on an important residue of the Rho switch 2 domain: glutamine 63 (Q63). Rho Q63 corresponds to Q61 of Ras. Glutamine 63 of Rho is implicated in the binding of a water molecule required for hydrolysis of the GTP gamma phosphate (Rittinger et al, 1997). Rho Q63 alone cannot stably maintain the water molecule during the transition state explaining the poor intrinsic GTP hydrolyzing activity of Rho (Rittinger et al, 1997). Associated to RhoGAP, which introduces an arginine residue (GAP arginine 85 ) close to Rho Q63, there is stabilization of Rho Q63 for the binding of the water molecule during the transition state resulting in a considerable acceleration of GTP hydrolysis (Rittinger et al, 1997). Q63 is thus a pivotal residue for Rho deactivation. Mutation of Q63 into another amino-acid decreases or totally blocks the GTPase activity of Rho and Rho associated to RhoGAP. We and others have shown that CNF1 exhibits a catalytic deamidase activity specific for Rho glutamine 63 (Flatau et al, 1997; Schmidt et al, 1997). Modification of Q63 to E63 in Rho blocks the intrinsic and GAP-stimulated hydrolysis of GTP resulting in the permanent activation of the GTP-binding protein (Flatau et al, 1997; Schmidt et al, 1997) (Figure 2).

\section{C3 and CNF1 are invaluable tools for studying how Rho is involved in cell regulation}

C3 effects on cultured cells brought the first indication that Rho could be implicated in the regulation of the actin 
cytoskeleton. Treatment of cells with C3 (at high concentrations to force the penetration of the enzyme into cells) induces a selective disorganization of actin stress fibers (Chardin et al, 1989) (Figure 3). The role of Rho in the control of cytoskeleton organization was then demonstrated by microinjection into cells of Rho either mutagenized (to make it permanently active) or modified in vitro by C3. C3 has been used to demonstrate that Rho controls smooth muscle contractility (Fujihara et al, 1997) and very recently it has been shown that blood pressure could be controlled mostly

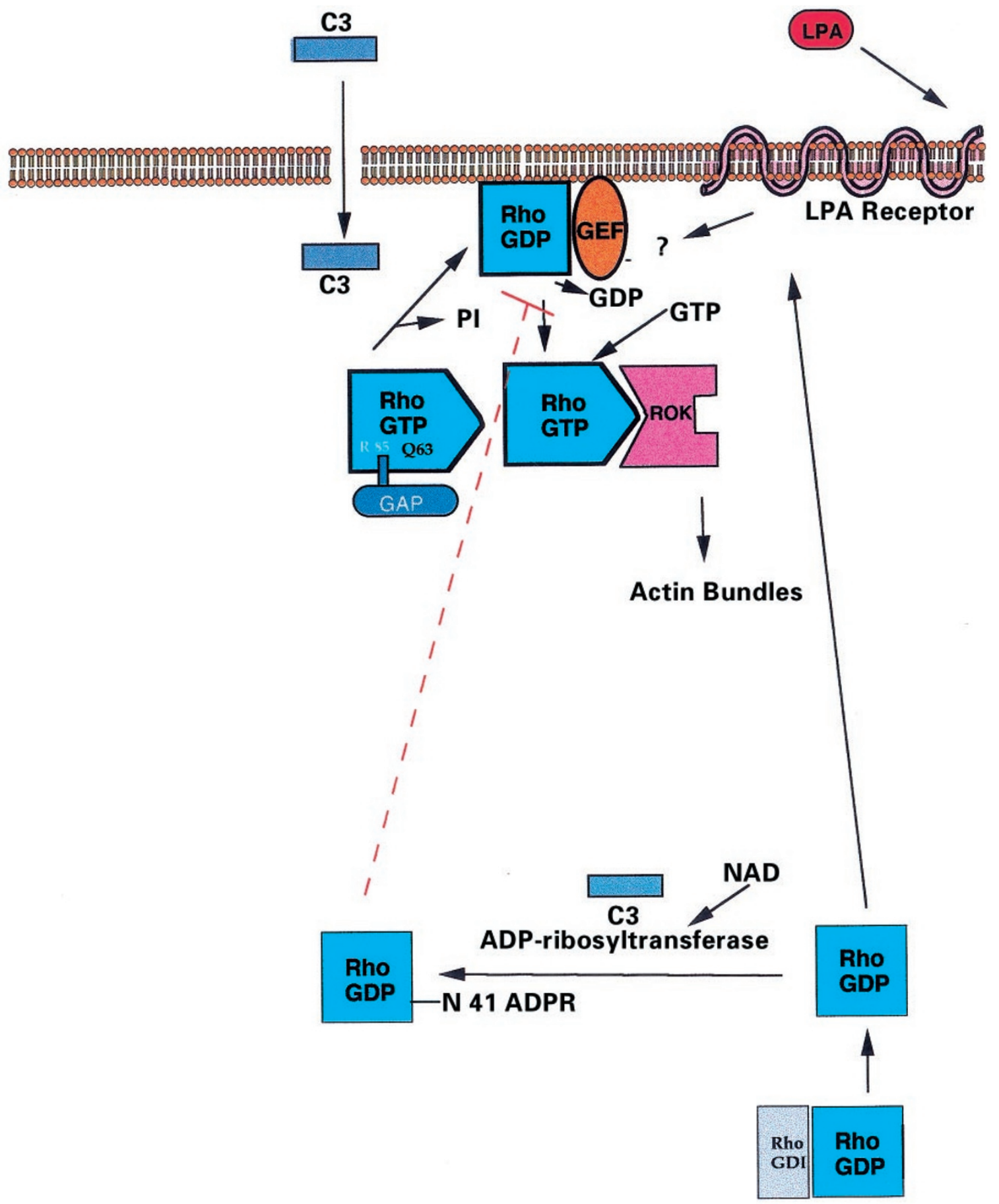

Figure 1 Activity of Clostridium botulinum exoenzyme $\mathrm{C} 3$ on Rho. $\mathrm{C} 3$ is not a toxin, thus it must be injected into the cytosol or introduced by chimeric toxins. Once in the cytosol C3 ADP-ribosylates Rho, preferentially the GDP bound form, on Rho asparagine 41. ADP-ribosylated Rho is unable to bind the cell membrane (red dotted line) thus it probably cannot be activated by the Rho GEF. However, in vitro ADP-ribosylated Rho can still bind the Rho downstream target ROK (black arrow) 
by Rho through blood vessel twitch (Uehata et al, 1997). Another important phenomenon induced by Rho activity and demonstrated by utilization of $\mathrm{C} 3$ is the inhibitory role of Rho in an early step of receptor-mediated endocytosis (Lamaze et al, 1996).
The role of Rho in the regulation of gene transcription has been analyzed using C3. From these studies it seems that Rho can control transcription at the level of the promotor serum responsive element (SRE) via activation of the serum response factor (SRF) (Hill et al, 1995).

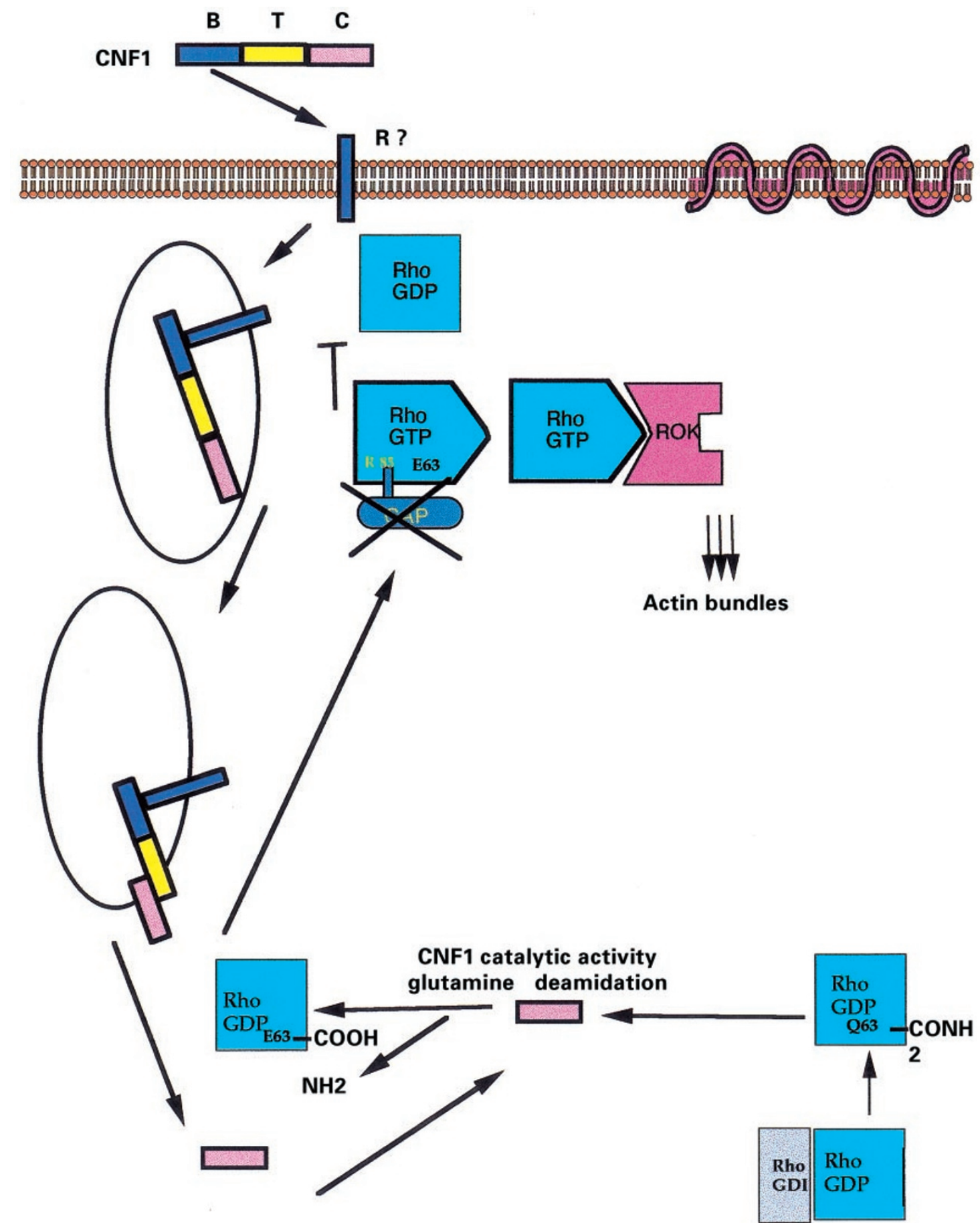

Figure 2 Activity of Escherichia coli CNF1 on Rho. CNF1 is organized into three domains B: cell binding, T: membrane translocation, C: catalytic. After binding to a membrane receptor, CNF1 is taken up by endocytosis and into an acidic intracellular compartment where the catalytic domain crosses the membrane, aided by the translocation domain. Once in the cytosol the catalytic CNF1 domain deamidates Rho glutamine 63 (Q63) into Rho glutamic acid 63 (E63). Rho E63 loses its ability to hydrolyse GTP into GDP in conjunction with RhoGAP. Rho being bound permanently to GTP activates the downstream Rho target ROK giving rise to stress fiber formation by microfilament bundling 


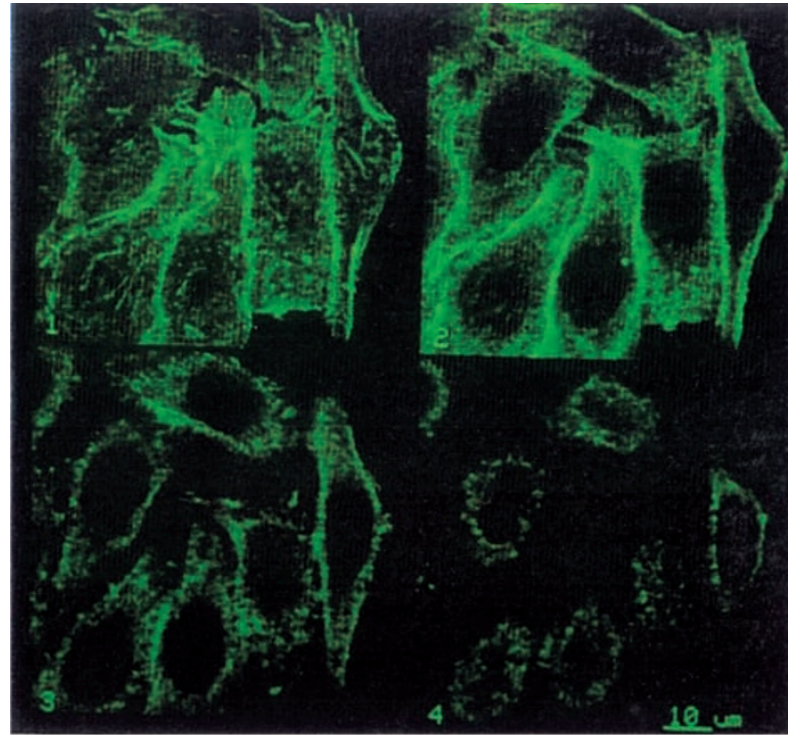

A
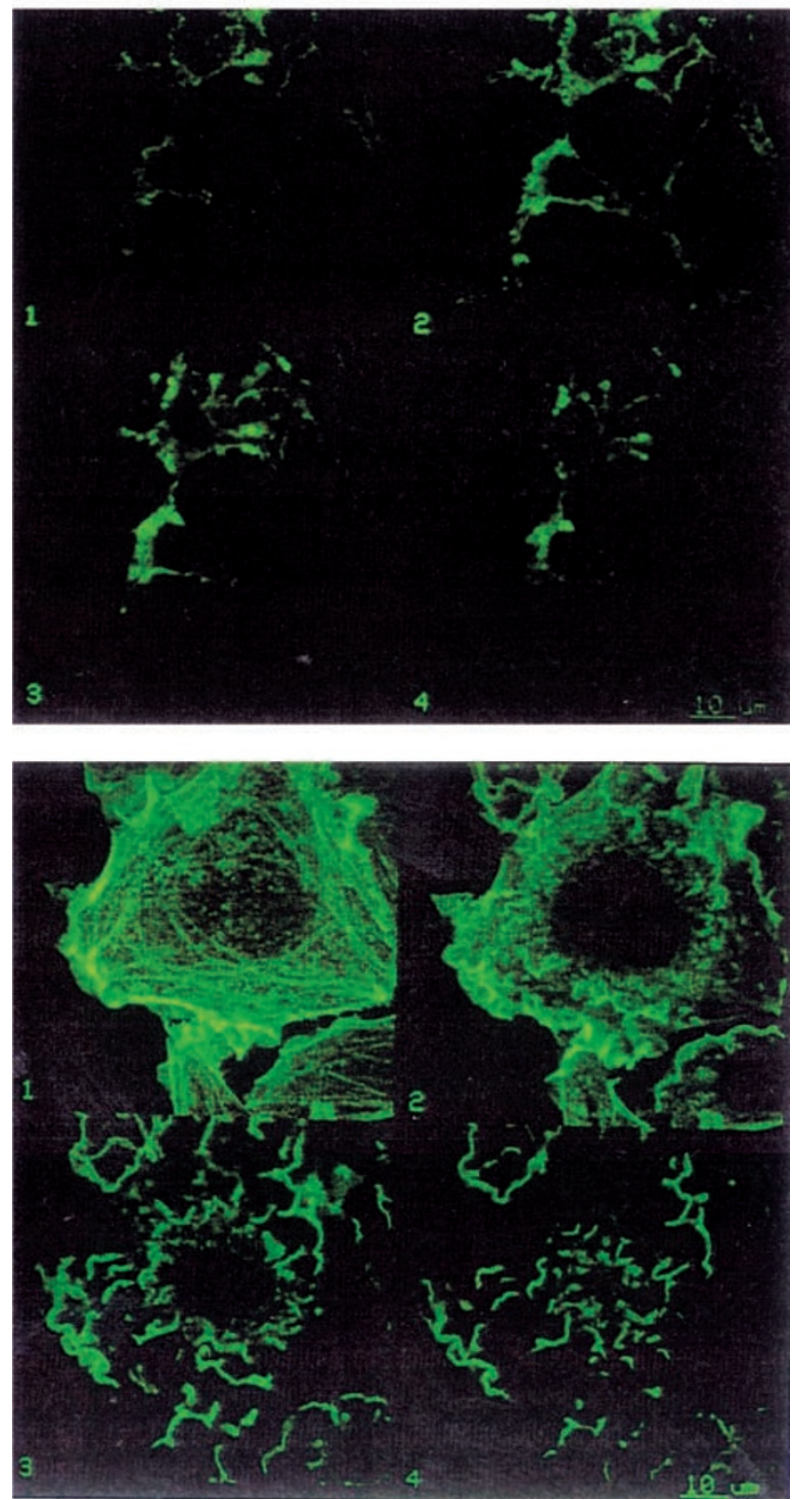

Table 1 Comparative cell activities of CNF1 and C3

\begin{tabular}{|c|c|c|}
\hline Activity & C3 (ref) & CNF1 (ref) \\
\hline sion & $\begin{array}{l}\text { inhi } \\
\text { (Rubin et }\end{array}$ & $\begin{array}{r}\text { ac } \\
\text { (Lacerda }\end{array}$ \\
\hline ytokinesis & (Rubin & $\begin{array}{r}\text { in } \\
\text { (Caprioli }\end{array}$ \\
\hline $\begin{array}{l}\text { tres } \\
\text { forr }\end{array}$ & $\begin{array}{r}\text { in } \\
\text { (Chardin }\end{array}$ & $\begin{array}{r}\text { activat } \\
\text { (Fiorentini et }\end{array}$ \\
\hline $\begin{array}{l}\text { ece } \\
\text { en }\end{array}$ & $\begin{array}{r}\text { ac } \\
\text { (Lamaze }\end{array}$ & \\
\hline inoc & tal, 1996) & ) (Senda \\
\hline ont & (l, 1997) & $\begin{array}{r}a \\
\text { (Fiorentir }\end{array}$ \\
\hline oca & (Aullo & $\begin{array}{r}\text { ac } \\
\text { (Fiorentir }\end{array}$ \\
\hline & , 1994) & (Fiorentir \\
\hline poptosis & $\begin{array}{c}\text { activates } \\
\text { (Henning et al, 1997) }\end{array}$ & (Fiorentini et al, 1998 \\
\hline Substr & $\begin{array}{c}\text { Rho } \\
\text { (Chardin et al, 1997) }\end{array}$ & $\begin{array}{c}\text { Rho } \\
\text { (Flatau et al, 1997) }\end{array}$ \\
\hline Co-substrate & (Chardin & r \\
\hline $\begin{array}{l}\text { Amino-acid } \\
\text { modified }\end{array}$ & $\begin{array}{c}\text { asparagine } 41 \\
\text { (Sekine et al, 1989) } \\
\text { ADP-ribosyltransferase } \\
\text { (Rubin et al, 1988) }\end{array}$ & $\begin{array}{c}\text { glutamine } 63 \\
\text { (Flatau et al, 1997) } \\
\text { deamidase } \\
\text { (Flatau et al, 1997) }\end{array}$ \\
\hline
\end{tabular}

However, activation of SRF by Rho does not depend on the MAP kinase or JNK/p38 pathways (Hill et al, 1995). Finally, C3 is able to block the entry of cells into G1 of the cell cycle indicating a role for Rho in the G0/G1 step (Olson et al, 1995).

CNF1 induces effects in cells opposite to those of $\mathrm{C} 3$ (Figure 3). It provokes a prominent bundling of actin stress fibers and multiplication of focal adhesion points (Fiorentini et al, 1988). This leads to cell spreading by the mechanism described above. CNF1 induces a large increase in enzymatic activity of the Pl-4 5-kinase (Fiorentini et al, 1997a) but curiously it is not possible to detect in cells an elevation of the PIP2 concentration (Fiorentini et al, 1997a). CNF1 also induces phosphorylation of $p 125^{\mathrm{FAK}}$ kinase and paxillin which are localized in focal adhesion contacts (Lacerda et al, 1997) and provokes the relocalization of myosin type 2 into stress fibers (Fiorentini et al, 1997a). Recently, it has been shown that a toxin which exhibits an enzymatic activity identical to that of CNF1 on Rho (Horiguchi et al, 1997) stimulates the formation of caveolae (Senda et al, 1997), whereas C3 microinjection into Xenopus ovocytes blocked selectively the non-clathrin dependent endocytic pathway (Schmalzing et al, 1996). Caveolae, whose major protein is caveolin, are small

Figure 3 Confocal fluorescence micrographs of epithelial HEp-2 cells stained for F-actin. Four different focal plans (from the bottom (1) to the top (4) of the cell) are shown for each sample. (A) Control cells; (B) cells exposed to $10^{-9} \mathrm{M} \mathrm{C3B}$ (Aullo et al, 1993) for $18 \mathrm{~h}$; (C) cells treated with $10^{-10} \mathrm{M}$ CNF1 for $48 \mathrm{~h}$. The main morphological effects provoked by these toxins in epithelial cells are: (B) cell retraction and actin cytoskeleton breakdown by C3, (C) cell spreading and actin assembly into ruffles and stress fibers by CNF1 

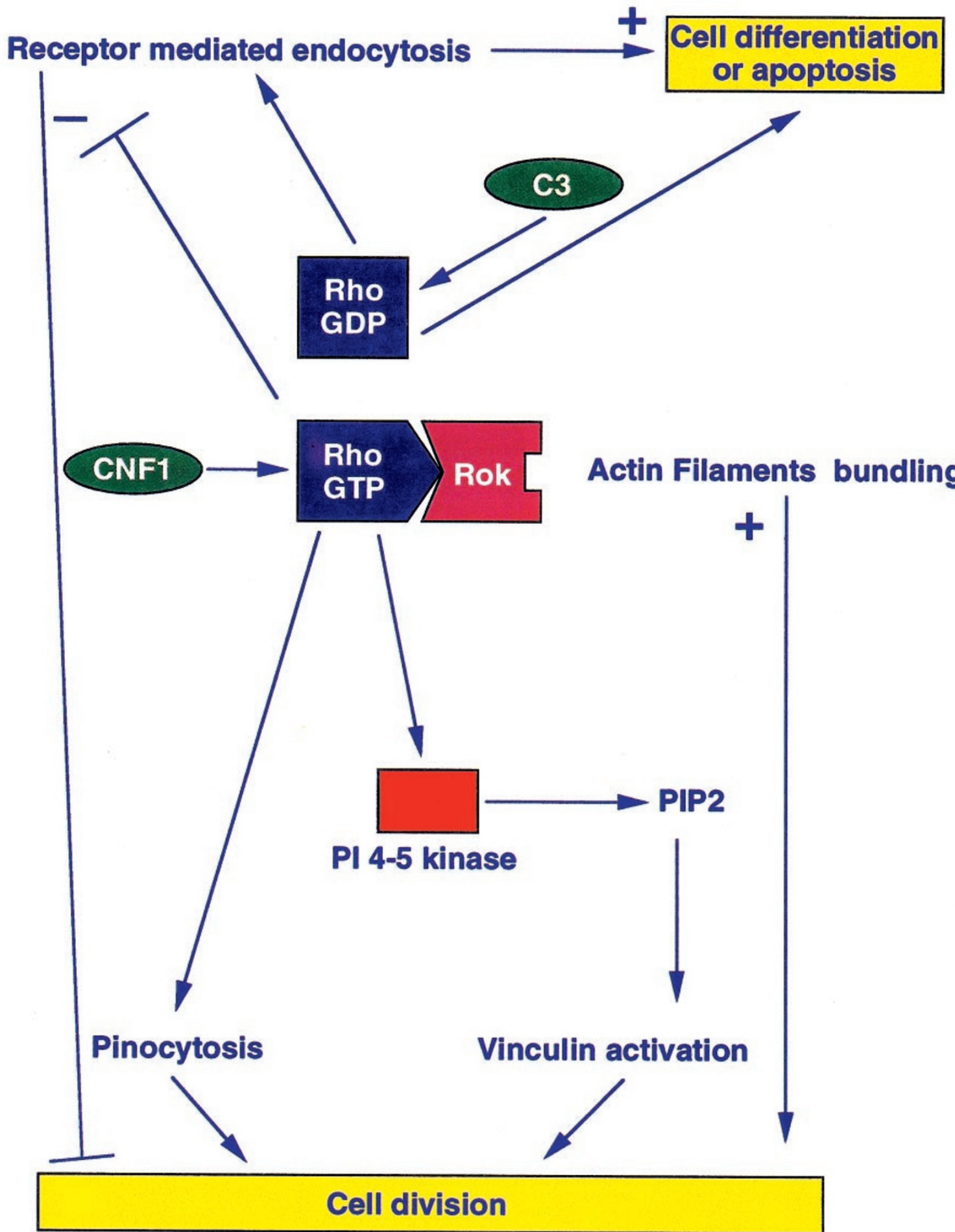

Figure 4 Possible pivotal role of Rho in cell multiplication, differentiation or apoptosis. Rho-GTP allows cell division by inhibiting receptor-mediated endocytosis and activating pinocytosis. This promotes filament bundling by both Rho kinase activation (filament bunding) and integrin cross-linking (vinculin activation) through PIP2 synthesis. Deactivation of Rho allows cell differentiation or apoptosis through microfilament disorganization, inhibition of pinocytosis and activation of receptor-mediated endocytosis. By permanently activating Rho, CNF1 provokes cell division and inhibits apoptosis. By inhibiting Rho, C3 blocks cell division but may allow either cell differentiation or apoptosis 
plasma membrane invaginations, which can give rise to vesicle formation (Parton, 1996). It seems that caveolin can traffic between the plasma membrane and the trans-Golgi compartment (Conrad et al, 1995). It is quite well established that caveolae are privileged sites where growth factor receptors and molecules implicated in signalling are concentrated (Lisanti et al, 1994; Simons and Ikonen, 1997). Rho may thus play an important role in controlling the steady state between the clathrin coated vesicles and caveolin endocytic pathways. We have summarized in Table 1 the cellular activities modulated by C3 and CNF1.

\section{Is Rho pivotal in driving cells toward multiplication, differentiation or apoptosis?}

Cells which constitute an organism must imperatively attach to a substrate to multiply and differentiate (Ruoslahti and Reed, 1994). If conditions for attachment to the extracellular matrix are not suitable, the cell may induce its own suicide (Hynes, 1992). In vertebrates, cell adhesion is mainly due to integrins. There are many different integrins, each of them recognizing a specific extracellular matrix. Interactions between integrins and extracellular substrate may induce proliferation, diferentiation or apoptosis. There are therefore signalling cascades initiated from integrins and acting at the level of gene expresion. Integrins act in the signalling cascade by phosphorylation of protein tyrosine residues (Clark and Brugge, 1995), allowing the binding of molecules called adaptors (Pawson, 1995). This allows the binding of other proteins and initiates a chain of signalling reactions, the best known being the one linking Ras to MAP kinases implicated in cell mitogenicity (Wittinghofer and Nassar, 1996).

In order to explain the role played by Rho in cell regulation we took into account observations on Rhodependent cellular effects reported by different groups using toxins like $\mathrm{C} 3$ or CNF1. First, the group of Sandra Schmidt has shown that Rho, bound to GTP, inhibits the formation of clathrin coats on the membrane, thus blocking endocytosis of cell receptors such as transferrin receptors (Lamaze et al, 1996). The same group has demonstrated an essential role for endocytosis mediated by growth factor receptors, such as EGF receptors, in the activation of these receptors (Viera et al, 1996). To summarize briefly, the inhibition of EGF receptor internalization stimulates their cell mitogenic activity, and increases the phosphorylation of the molecule called shc which can recruit adaptor proteins (Viera et al, 1996). On the other hand, internalization by clathrin coated vesicles of these receptors increases their ability to activate the PI3 kinase (Viera et al, 1996). This observation may be linked to that made by the group of Filippo Giancotti who reported that certain integrins induce cellular multiplication by provoking, through phosphorylation of tyrosine residues, the activation of the shc molecule (Wary et al, 1996). Shc then activates, by the Ras pathway, the MAP kinase cascade thus activating cell division (Wary et al, 1996). Curiously, however, shc in the Giancotti experiments was immunoprecipitated together with caveolin (Wary et al, 1996). The existence of caveolin in the induction of shc phosphorylation by integrins is explained by recruitment of both shc and a kinase by caveolae at the level of focal adhesion points (Wary et al, 1996). As discussed above, once activated by a CNF1-like toxin, Rho seems to increase the number of caveolae at the level of cell surface (Senda et al, 1997). Is it possible that Rho, by modulating the efficiency of endocytotic pathways together with its ability to cluster integrins, plays a central role in the decision of a cell to proliferate, differentiate or commit suicide? (Figure 4).

Thus, we propose the following scenario: a signal induced by an extracellular factor (for instance, LPA) will activate the receptor linked to Rho. Rho will induce in turn both fasciculation of actin stress fibers through activation of myosin (Chrzanowska-Wodnicka and Burridge, 1996) and the binding of actin filament to vinculin, by activation of this molecule with PIP2 (Gilmore and Burridge, 1996) thus allowing clustering of integrins (Chrzanowska-Wodnicka and Burridge, 1996). This mechanism will ensure the activity for signalling on an extracellular matrix. Concomitantly activated-Rho will increase the traffic and synthesis of caveolae (Senda et al, 1997) bringing shc and tyrosine kinases to the level of integrins (Wary et al, 1996). Moreover, it will inhibit the formation of clathrin coated vesicles (Lamaze et al, 1996) forcing receptors implicated in the control of mitogenicity to remain at the cell surface thus increasing their capacity to stimulate cell division (Viera et al, 1996).

After the arrest of the activating Rho signal, the Rho cascade will stop and the integrins will be dispersed by myosin light chain dephosphorylation and by the unbinding of vinculin on actin filaments. A new signal (required for differentiation) activating a regulatory cascade different from that of Rho will provoke the binding and clustering of a new set of integrins and the binding to a new extracellular matrix. Once Rho is deactivated, the endocytotic pathway mediated by clathrin will regain its activity and the receptors implicated in the mitogenicity will be inhibited by their own endocytosis. However, activation of the PI3 kinase by receptors, due to endocytosis (Viera et al, 1996), might stimulate new cascades of signalling such as those of Rac and Cdc42. This will be the case, for instance, if the new set of integrins recognize an extracellular matrix required for cell differentiation. On the other hand, if this extracellular matrix was not produced, the cascade of p38 kinases ending in apoptosis will be triggered by Rac or Cdc42 (Xia et al, 1995) to avoid a phenotypic error or an abnormal cellular multiplication. According to our model, activation of Rho will protect against apoptosis whereas inhibition of this GTP-binding protein, together with certain stimuli, will result in cell death. In agreement with this model, it has been shown that inhibition of Rho either by C3 (Bobak et al, 1997) or by Clostridium difficile toxin B (Gomez et al, 1997) is able to induce apoptosis in different cell types, whereas CNF1, by activating Rho, increases $\mathrm{Bcl}-2$ expression and strongly protects against UVB induced apoptosis (Fiorentini et al, 1997b, 1998). Accordingly, when the exoenzyme C3 gene was expressed under the control of a $\mathrm{T}$ cell differentiation promotor, thymic cells from transgenic mice underwent apoptosis (Henning et al, 1997). In contrast with this view, it has been reported, for 
example, that transfection of the dominant active version of Rho (Rho val 14) into 3T3 cells growing in the absence of serum was able to induce apoptosis (Jimenez et al, 1995). Further studies should be undertaken to solve this controversy.

A mitogenic signal must induce strong and constant phosphorylation to induce proliferation. The double signal from stimulated integrins and growth factor receptors activating the MAP kinase pathway, will explain the strong and sustained phosphorylation required for the entry of cells into the cell cycle. In our model, Rho might have no activating role per se on transcription, as demonstrated for Ras, Rac and Cdc42, but could play a role by coordinating the actin cytoskeletal organization together with the endocytic traffic in order to modulate the activity of certain kinases. In keeping with this model it seems that Rho exerts a permissive but not decisive effect on MAP kinase activation (Frost et al, 1996).

\section{Conclusions}

Bacterial toxins acting on the GTP-binding protein Rho, such as C3 and CNF1, are invaluable tools to study the functions of this regulatory protein whose pivotal role in cell homeostasis is becoming more and more evident.

The discovery that a bacterial toxin such as CNF1 (produced by pathogenic bacteria found in human and animal infections) induces an amino-acid modification which activates a small GTP-binding protein of the Ras superfamily leads us to pose the following provoking question: might certain tumors have an infectious origin?

\section{Acknowledgements}

This work was partially supported by National Research Council (CNR)Strategic Project 'Cell cycle and apoptosis', U.O. 11, grant no. 97.04906.ST74 to C.F. and by funds from INSERM to P.B.

\section{References}

Aktories K, WellerU and Chatwal GS (1987) Clostridium botulinumtype C produces a novel ADP-ribosyltransferase distinct to botulinum C2 toxin. FEBS Lett. 212: $109-113$

Amano M, Chihara K, Kimura K, Fukuta Y, Nakamura N, Matsuura Y and Kaibuchi K (1997) Formation of actin stress fibers and focal adhesions enhanced by Rho kinase. Science 275: 1308-1311

Aullo P, Giry M, Olsnes S, Popoff MR, Kocks C and BoquetP (1993) A chimerictoxin to study the role of the $21 \mathrm{kDa}$ GTP-binding protein Rho in the control of actin microfilament assembly. EMBO J. 12: 921-931

Bobak D, Moorman J, Guanzon A, Gilmer L and Hahn C (1997) Inactivation of the small GTPase Rho disrupts cellular attachment and induces adhesion dependent and adhesion independent apoptosis. Oncogene 15: 2179-2189

BoquetP, Popoff MR, Giry M, Lemichez E and Bergez-Aullo P (1995) Inhibition of p21 Rho in intact cells by $\mathrm{C} 3$ diphtheria toxin chimera proteins. Methods in Enzymol. 256: $297-306$

Caprioli A, Falbo V, Roda LG, Ruggeri FM and Zona C (1983) Partial purification and characterization of an Escherichia coli toxic factor that induces morphological cell alterations. Infect. Immun. 39: 1300-1306

Chang EH, Furth ME, Scolnick EM and Lowry DR (1982) Tumorigenic transformation of mammalian cells induced by a normal human gene homologous to the oncogene of Harvey murine sarcoma virus. Nature, 297: 479-483
Chardin P, Boquet P, Madaule P, Popoff MR, Rubin EJ and Gill DM (1989) The mammalian $G$ protein Rho $C$ is ADP-ribosylated by Clostridium botulinum exoenzyme $\mathrm{C} 3$ and affects actin microfilaments in Vero cells. EMBO J. 8: 10871092

Chong LD, Traynor-Kaplan A, Bokoch GM and Schwartz MA (1994) The small GTPbinding protein Rho regulates a phosphatidylinositol4-phosphate5-kinase in mammalian cells. Cell 79: 507-513

Chrzanowska-Wodnicka Mand Burridge K (1996) Rho-stimulated contractility drives the formation of stress fibers and focal adhesions. J. Cell Biol. 6: 1403-1415

Clark EA and Brugge JS (1995) Integrin and signal transduction pathways: the road taken. Science 268: 233-239

Conrad PA, Smart EJ, Ying YS, Anderson RGW and Bloom G (1995) Caveolin cycles between plasma membrane and the Golgi complex by microtubule-dependent and microtubule-independent steps. J. Cell Biol. 131: 1421-1433

Cramer LP and Mitchison TJ (1995) Myosin is involved in postmitotic cell spreading. J. Cell Biol. 131: 179-189

Donelli $G$ and Fiorentini C (1997) Cytotoxic necrotizing factors (Escherichia coli). In: Guidebook to protein toxins and their use in Cell Biology. Rappuoli R and Montecucco C., eds (Oxford University Press) pp. 69-71

Downward J (1990) The Ras superfamily of small GTP-binding proteins. Trends in Biochem. Sci 15: 469-472

Fiorentini C, Arancia G, Caprioli A, Falbo V, Ruggeri FM and Donelli G (1988) Cytoskeletal changes induced in Hep-2 cells by the cytotoxic necrotizing factor of Escherichia coli. Toxicon 26: 1047-1056

Fiorentini C, Donelli G, Matarrese P, Fabbri A, Paradisi S and Boquet P (1995) Escherichia coli cytotoxic necrotizing factor 1: evidence for induction of actin assembly by constitutive activation of the p21 Rho GTPase. Infect. Immun. 63: 3936-3944

Fiorentini C, Fabbri A, Flatau G, Donelli G, Matarrese P, Lemichez E, Falzano L and Boquet $\mathrm{P}$ (1997a) Escherichia colicytotoxic necrotizing factor 1 (CNF1), a toxin that activates the Rho GTPase. J. Biol. Chem. 272: 19532-19537

Fiorentini C, Fabbri A, Matarrese P, Falzano L, Boquet P and Malorni W (1997b) Hinderance of apoptosis and phagocytic behaviour induced by $E$. coli cytotoxic necrotizing factor 1 (CNF1): two related activities in epithelial cells. Biochem. Biophys. Res. Comm. 241: 341-346

Fiorentini C, Matarrese P, Straface E, Falzano L, Fabbri A, Donelli G, Cossarizza A, Boquet $P$ and Malorni W (1998) Toxin-induced activation of Rho GTP-binding protein increases $\mathrm{Bcl}-2$ expression and influences mitochondrial homeostasis. Exp. Cell Res., in press

Flatau G, Lemichez E, Gauthier M, Chardin P, Paris S, Fiorentini C and Boquet P (1997) Toxin-induced activation of the $G$ protein Rho by deamidation of glutamine. Nature 387: 729-733

Frost JA, Xu S, Hutchinson MR, Marcus S and Cobb M (1996) Actions of Rho family small G-proteins and p21 activated protein kinases on mitogen-activated protein kinases members. Mol. Cell Biol. 16: 3707-3713

Fujihara H, Walker LA, Gong MC, Lemichez E, Boquet P, Somlyo AV and Somlyo AP (1997) Inhibition of RhoA translocation and calcium sensitization by in vivo ADP. ribosylation with the chimeric DC3B. Mol. Biol. Cell 8: 2437-2447

Fukumoto Y, Kaibuchi K, Hori Y, Fujioka H, Araki S, Ueda T, Kikuchi A and Takai Y (1990) Molecular cloning and characterization of a novel type of regulatory protein (GDI) for the Rho proteins, Ras p21-like small GTP-binding proteins. Oncogene 5: $1321-1328$

Gallwitz D, Donath C and Sander C (1983) A yeast gene encoding a protein homologous to the human c-ras:bas proto-oncogene product. Nature 306: 704 707

Gilmore AP and Burridge K (1996) Regulation of vinculin binding to talin and actin by phosphatidyl-inositol 4-5 biphosphate. Nature 381: $531-535$

Gomez J, Martinez C, Giry M, Garcia A and Rebollo A (1997) Rho prevents apoptosis through $\mathrm{Bcl}-2$ expression: implication for interleukin-2 receptor signal transduction. Eur. J. Immunol. 27: 2793-2799

Hartwig JH, Bokoch GM, Carpenter CL, Jeanmey PA, Taylor LA, Toker A and Stossel TP (1995) Thrombin receptor ligation and activated Rac uncap actin filament barbed ends through phosphoinositide synthesis in permeabilized human platelets. Cell 82: 643-653

Henning SW, Galandrini R, Hall A and Cantrell DA (1997) The GTPase Rho has a critical regulatory role in thymus development. EMBO J. 16: 2397-2407

Hill CS, Wynne J and Treisman R (1995) The Rho family GTPases RhoA, Rac1 and Cdc42Hs regulate transcriptional activation by SRF. Cell 81: 1159-1170 
Hirao M, Sato N, Kondo T, Yonemura S, Monden M, Sasaki T, Takai Y, Tsukita S and Tsukita S (1996) Regulation mechanism of ERM (ezrin/radixin/moesin) protein/ plasma association: possible involvement of phosphatidylinositol turnover and Rho-dependent signaling pathway. J. Cell Biol. 135: 37-51

Horiguchi Y, Inoue N, Masuda M, Kashimoto T, Katahira J, Sugimoto N and Matsuda M (1997) Bordetella bronchiseptica dermonecrotizing toxin induces reorganization of actin stress fibers through deamidation of GIn-63 of the GTP-binding protein Rho. Proc. Natl. Acad. Sci. USA 94: 11623-11626

Hynes RO (1992) Integrins: versatility, modulation and signalling in cell adhesion. Cell 69: 11-25

Ishizaki T, Maekawa M, Fujisawa K, Okawa K, Iwamatsu A, Fujita A, Watanabe N Saito Y, Kakizuka A, Morii N and Narumiya S (1996) The small GTP-binding Rho binds to and activates a $160 \mathrm{kDa}$ ser/thr protein kinase homologous to myotonic dystrophy kinase. EMBO J. 15: 1885-1893

Jimenez B, Arends M, Esteve P, Perona R, Sanchez R, Ramony CajalS, Wyllie A and Lacal JC (1995) Induction of apoptosis in NIH3T3 cells after serum deprivation by overexpression of Rho-p21, a GTPase protein of the Ras superfamily. Oncogene 10: $811-816$

Kimura K, Ito M, Amano M, Chihara K, Fukuta Y, Nakafuku M, Yamamori B, Feng J, Nakano T, Okawa K, Iwamatsu A and Kaibuchi K (1996) Regulation of myosin phosphatase by Rho and Rho-associated kinase (Rho-kinase). Science 273: $245-247$

Lacerda HM, Pullinger GD, Lax AJ and Rozengurt E (1997) Cytotoxic necrotizing factor 1 from Escherichia coli and dermonecrotic toxin from Bordetella bronchiseptica induce p21 Rho-dependent tyrosine phosphorylation of foca adhesion kinase and paxillin in Swiss 3T3 cells. J. Biol. Chem. 272: 9587-9596

Lamaze C, Chuang TH, Terlecki LJ, Bokoch GM and Schmid SL (1996) Regulation of receptor mediated endocytosis by Rho and Rac. Nature 382: 177-179

Lisanti MP, Scherer PE, Tang Z and Sargiacomo M (1994) Caveolae, caveolin, and caveolin rich membrane domains: a signalling hypothesis. Trends Cell Biol. 4: $231-235$

Mackay DJG, Esch F, Furthmayr H and Hall A (1997) Rho-and Rac-dependent assembly of focal adhesion complexes and actin filament in permeabilized fibroblasts: an essential role for ezrin/radixin/moesin proteins. J. Cell Biol. 138: $927-938$

Madaule P and Axel R (1985) A novel ras-related gene family. Cell 41: 31 - 40

Matsui T, Amano M, Yamamoto T, Chihara K, Nakafuku M, Ito M, Nakano T, Okawa K, Iwamatsu A and Kaibuchi K (1996) Rho-associated kinase, a novel serine/ threonine kinase, as a putative target for the small GTP-binding protein Rho. EMBO J. 15: 2208-2216

Milburn M, Tong L, de Vos A, Brunger A, Yamaizumi Z, Nishimura S and Kim SH (1990) Molecular switch for signal transduction: structural differences between active and inactive forms of protooncogenic ras proteins. Science 247: 939-945

Olson FM, Ashworth A and Hall A (1995) An essential role for Rho, Rac, and Cdc42 GTPases in cell cycle progression through G1. Science 269: 1270-1272

Parton RG (1996) Caveolae and caveolins. Curr. Op. Cell Biol. 8: 542-548
Paterson HF, Self AJ, Garrett MD, Just I, Aktories Kand Hall A (1990) Microinjection of recombinant p21Rho induces rapid changes in cell morphology. J. Cell Biol. 111: $1001-1007$

Pawson T (1995) Protein modules and signalling networks. Nature 373: 573-580

Ren X, Bokoch GM, Traynor-Kaplan A, Jenkins GH, Anderson RA and Schwartz MA (1996) Physical association of the small GTPase Rho with a $68 \mathrm{kDa}$ phosphatidylinositol 4-phosphate 5-kinase in Swiss 3T3 cells. Mol. Biol. Cell. 7: $435-442$

Rittinger K, Walker PA, Eccleston JF, Smerdon SJ and Gamblin SJ (1997) Structure at 1,65 Angstrom of RhoA and its GTPase-activating protein in complex with a transition state analog. Nature 389: 758-762

Rubin EJ, Gill DM, Boquet P and Popoff MR (1988) Functional modification of a 21kilodalton $\mathrm{G}$ protein when ADP-ribosylated by exoenzyme $\mathrm{C} 3$ of Clostridium botulinum. Mol. Cell Biol. 8: 418-426

Ruoslahti E and Reed JC (1994) Anchorage-dependence, integrins and apoptosis. Cell 77: 477-478

Schmalzing G, Richter H-P, Hansen A, Schwartz W, Just I and Aktories K (1996) Involvement of the GTP-binding Rho in constitutive endocytosis in Xenopus laevi ovocytes. J. Cell Biol. 130: 1319-1332

Schmidt G, Sehr P, Wilm M, Selzer J, Mann M and Aktories K (1997) Gln63 of Rho is deamidated by Escherichia colicytotoxic necrotizing factor-1. Nature 387: 725728

Sekine A, Fujiwara M and Narumiya S (1989) Asparagine residue in the Rho gene product is the modification site for botulinum ADP-ribosyltransferase. J. Biol. Chem. 264: 8602-8605

Senda T, Horiguchi Y, Umemoto M, Sugimoto N and Matsuda M (1997) Bordetella bronchiseptica dermonecrotizing toxin, which activates a small GTP-binding Rho, induces membrane organelle proliferation and caveolae formation. Exp. Cell Res. 230: 163-168

Simons Kand lkonen E (1997) Functional rafts in cell membranes. Nature 387: 569 572

Uehata M, Ishisaki T, Satoh H, Ono T, Kawahara T, Morishita T, Tamakawa H, Yamagami K, Inui J, Maekawa M and Narumiya S (1997) Calcium sensitization of smooth muscle mediated by Rho-associated protein kinase hypertension. Nature 389: $990-994$

Viera AV, Lamaze C and Schmid SL (1996) Control of EGF receptor signaling by clathrin-mediated endocytosis. Science 274: 2086-2089

Wary KK, Mainiero F, Isakoff SJ, Marcantonio E and Giancotti FG (1996) The adaptor protein shc couples a class of integrins to the control of cell cycle progression. Cell 87: $733-743$

Wittinghofer A and Nassar N (1996) How ras-related proteins talk to their effectors. Trends in Biochem. Sci. 21: 488-491

Xia Z, Dickens M, Raingeaud J, Davis RJ and Greenberg ME (1995) Opposing effects of ERK and JNK-p38 kinases on apoptosis. Science 270: 1326-1329

Zerial M and Huber LA (1995) Guidebook to the small GTPases. Oxford University Press, Oxford 